\title{
Implementation of Real-Time Monitoring of Working Conditions to Improve the Monitoring Level of VOCs Pollution
}

\author{
Zhipeng Zhuang ${ }^{1,2}$, Bing Hong ${ }^{2}$, Weiming Liu², Tongsheng Chen $^{2}$, and Baoyuan Huang ${ }^{*}, 2$ \\ ${ }^{1}$ Guangzhou Huake Environmental Protection Engineering Co., Ltd., Guangzhou 510655, China \\ ${ }^{2}$ South China Institute of Environmental Sciences. MEE, Guangzhou, 510655, China
}

\begin{abstract}
It is imperative to improve the monitoring level of organic waste gas pollution by carrying out real-time monitoring of working conditions, which is in line with national policy and social development. Due to the complex composition, widespread distribution of pollution sources and unorganized emission, it is difficult to control organic waste gas effectively only by current emission regulation. The government should follow up continuously and in real time the status of environmental protection equipment opened by polluting enterprises when the technical conditions permits. It is realized the real-time data collection, transmission, storage and form various reports to monitor, check and judge the working status. Through the implementation of the real-time monitoring of working conditions, the supervision efficiency is improved, the management means is enriched, and a great deal of manpower and management costs are saved.
\end{abstract}

\section{Current situation of monitoring VOCs pollution}

\subsection{Hazards of VOCs}

Vocs, one of the main sources of air pollution, are composed of more than 120 kinds of organic gases with different proportions and can cause secondary pollution such as photochemical smog. A series of photochemical reactions occur among VOCs and nitrogen oxide and other suspended chemicals in the air, mainly producing ozone, which forms photochemical smog, thus causing photochemical pollution and harm on a larger scale It is also one of the most important factors of smog formation.

\subsection{Current situation of VOCs pollution treatment}

In the list of key enterprises of Volatile organic compound, there are 209 enterprises (15\% of the total) in Guangzhou, and there are about 5,000 VOCs-related enterprises in the city. At present, VOCs pollution in Guangzhou is mainly concentrated in Baiyun District, Huangpu District, Zengcheng and Conghua District. Under the pressure of the increasing environmental awareness of enterprises and the high pressure of the central supervision of environmental protection in recent years, many enterprises have increased pollution control measures as required.

\subsection{Current situation of VOCs pollution monitoring}

Vocs pollution monitoring, the main work includes checking whether the equipment is open, monitoring whether the equipment is working properly and monitoring whether the end of the emission is up to standard. Because of the particularity of VOCs treatment (can start and stop at any time, and the effect of treatment is immediate), it is difficult for the inspectors to find problems in daily monitoring.

\section{Problems of VOCs pollution monitoring}

\subsection{Problems existing in polluting enterprises}

After investigation, due to the reasons of saving the cost of environmental protection treatment, the following problems are common: 1) the environment protection facilities are installed, but the VOCs exhaust pipes are not connected to the treatment facilities, and the Enterprises Directly Emit Pollutants; 2) the environment protection facilities are not opened at the same time as the pollution production facilities of the enterprises (only during the inspection of the environment protection), the VOCs are almost discharged directly; 3) the environment protection facilities are opened only partly, the operation of the facilities is not in direct proportion to the degree of pollution; 4) the environment protection facilities are not maintained and repaired for a long time, and the treatment efficiency of pollutants can not meet the design 
requirements. Due to the high price of VOCs monitoring equipment, expensive equipment maintenance, imperfect monitoring technology and other factors, most VOCs polluters can not afford to install pollution monitoring equipment, and the government can not afford to install pollution monitoring equipment for free.

\subsection{Problems existing in the supervision of the competent administrative department}

Because VOCs have complex components, widely distributed pollution sources and unorganized emission, it is difficult to control VOCs by current emission regulation. Although in recent years our country has continuously increased the policy input to VOCs, and has taken certain measures from the whole policy system, monitoring standard and so on, there are still many problems on the whole, mainly manifest in the lack of basic data, laws and regulations lag, emission standards and monitoring standards are not perfect and control technology needed to be updated.

\subsubsection{Lack of basic data}

Compared to other pollutants, VOCs are not included in the system of environmental statistics management, and monitoring equipment has been behind the lack of basic data. Vocs emission comes from many industries. It is difficult to pay attention to them effectively under the old pollution control system which is limited to conventional pollutants. Due to the inadequate coverage of monitoring equipment, the environmental protection authorities currently have little basic information on the distribution, emission intensity and treatment of VOCs from industrial enterprises, and lack of basic data on the characteristics of regional and National Environmental Air VOCs pollution The emission status is not clear, the existing data can not fully reflect the true situation of pollution.

\subsubsection{Laws and regulations lag behind}

The control of VOCs in China is still at the initial stage, and the problems of weak systematicness, poor industry pertinence and incomplete control are more prominent. The Old Air Pollution Control Act did not mention the inclusion of VOCs into the scope of regulation, and the Regulations on VOCs pollution control lacked specific requirements on environmental access, day-to-day regulation and risk prevention There is no systematic and effective system for the prevention and control of toxic and hazardous waste pollution and no uniform and standardized punishment for enterprises that emit excessive amounts of pollutants, do not install monitoring equipment as required, and emit excessive amounts of pollutants The lag of laws and regulations has seriously hindered the normal development of the industry.

\subsubsection{The emission standard is not perfect}

Vocs pollution is complex and comes from many sources, so it is difficult to monitor and control VOCs pollution. Before 2010, VOCs were not included in China's air quality standards, and the VOCs emission standards of typical industries were obviously inadequate. The monitoring and analysis methods of air pollution sources and air VOCs are mainly based on the reference of foreign standards, but lack of unified technical standards and comparability of different research results, which increase the difficulty of pollution control. In control technology, mainly to imitate and track foreign technology, lack of China's own situation with intellectual property rights control technology.

\subsubsection{Understaffed}

In recent years, reports of sudden death due to overwork by law enforcement personnel in environmental protection posts have been common, mainly due to the insufficient staffing and excessive workload of the environmental protection departments in cities and towns It is impossible to check all the polluting enterprises one by one. For example, the Environmental Protection Bureau in a district has five departments and 25 employees, but there are more than 2,000 polluting enterprises in its district. They have no time to supervise every factory.

\subsubsection{Relationships}

China is a state of etiquette, but in today's increasingly developed society, etiquette changes slowly. Part of the grass-roots supervisory staff and enterprises have a myriad of relationships, in the process of monitoring in advance notice, cursory or ignored the situation is common.

To sum up, there are many problems in the process of VOCs regulation. These problems not only make the investment of environmental protection treatment become a joke, but also make the ability of supervision and management of government departments be questioned. Therefore, it is imperative to seek a reasonable, cheap and efficient dynamic monitoring method, optimize and improve the monitoring efficiency of the environment, and strengthen the real-time monitoring of such industrial pollution sources.

\section{Necessity and feasibility of carrying out real-time monitoring of working conditions}

In order to find and punish environmental pollution problems in a timely manner, put an end to illegal discharge accidents such as illegal discharge and discharge leakage, and strengthen real-time supervision of polluting enterprises, effectively solve the problem of pollution and disturb people, and ensure the establishment of long-term mechanism of prevention and control work. The government should follow up 
continuously and in real time the status of environmental protection equipment opened by polluting enterprises when the technical conditions permit.To realize the real-time data collection, transmission, storage and form various reports to monitor, check and judge the working status. Working Condition Monitoring, can be called environmental protection facilities (equipment) working condition real-time monitoring platform. Its main objective is to serve the competent environmental authorities to improve the efficiency of environmental monitoring, improve environmental protection project management process data and provide environmental pollution early warning platform. Working condition monitoring should have the characteristics of low cost, real-time accuracy, real-time reliability and recording early warning.

\subsection{Cheap to build}

Work on professional information such as environmental protection project environmental impact assessment, pollution enterprise integration policy, environmental control measures acceptance scheme, etc. At the same time, the pollution status, control measures and related control process selection were studied. Therefore, it is feasible to record the necessary parameters during the operation of pollution control facilities by cheaper probes to judge the operation of pollution generating equipment and environmental protection treatment equipment. The monitoring system can completely replace the on-line monitoring equipment at the end of the exhaust gas, and reflect the basic situation of the exhaust gas emission at the end by the relative value of the working condition. Since the operating condition monitoring price is much cheaper than the on-line monitoring equipment of the exhaust gas terminal (the on-line monitoring equipment is about 450,000 yuan a set, while the operating condition monitoring equipment is about 20,000 yuan a set, and the operating and maintenance cost is about 5:1), therefore, in the promotion process, it is easier for both companies and governments to accept.

\subsection{Real-time, accurate, reliable and recorded early warning}

The monitoring of working conditions must satisfy the following purposes: 1) to strengthen the monitoring of pollution source treatment and eliminate the hidden danger of pollution accidents by monitoring the working conditions of the equipment; 2) to reflect the phenomenon of the environment protection treatment facilities being shut down or idle through the verification of the Operation Records; 3) to provide the basis for the targeted law enforcement inspection by the competent administrative departments through the real-time alarm of working conditions / historical tracing. Therefore, the VOCs can be avoided because of the characteristics of start and stop at any time lead to monitoring difficult problems, avoid enterprises because of cost savings and governance process fraud, avoid other human factors.

\section{Conclusion}

The real-time monitoring of working conditions can be realized by collecting the necessary signals from the pollution control facilities and the production workshops of enterprises. The data of pollution and pollution control are transferred to the cloud computing server through analog-to-digital conversion by Internet of Things and cloud computing technology. The cloud computing server carries out the balance of data analysis, computer production and pollution control, and outputs the results of the computing or early warning, thus the environmental protection management department can grasp the real-time situation of pollution control facilities on the Internet. By strengthening the environmental management, the Environmental Protection Department can improve the efficiency of supervision, enrich the management means, save a lot of manpower and management costs.

\section{Reference}

1. Volatile organic compound for key industries: Ministry of Ecology and Environment, 2019, Beijing.

2. Volatile Organic compound and emission reduction programme of Guangdong Province (2018-2020): Department of Ecological Environment of Guangdong Province, 2018, Guangzhou.

3. National Inventory of Advanced Pollution Control Technologies (field of air pollution control): Ministry of Ecological Environment, 2018, Beijing.

4. State Council of the People's Republic of China's guidance on actively promoting Internet plus action, 2015, Beijing.

5. Circular of the General Office of the People's Government of Guangdong Province of the People's Republic of China, on Printing and distributing the implementation plan for the construction of the ecological Environmental monitoring of Guangdong Province, 2017.Guangzhou. 